\title{
ASSESMENT OF PATIENT SATISFACTION OF IMPLANTABLE VENOUS PORT CATHETER USE: A SURVEY-BASED STUDY
}

\author{
Begüm Söyleyici', Ece Şenyiğit ${ }^{1}$, Nur Gülce İşkan ${ }^{1}$ Fazlı Yanık²
}

${ }^{1}$ Trakya University Faculty of Medicine, Edirne, TURKEY

${ }^{2}$ Department of Thoracic Surgery, Trakya University Faculty of Medicine, Edirne, TURKEY

\section{ABSTRACT}

Aims: Implantable venous port catheter is a widely used clinical tool with plenty of objectives such as parenteral nutrition, taking blood sample, management of medicines used in chemotherapy. The aim of this study is to evaluate patient satisfaction regarding implantable venous port catheter for chemotherapy treatment.

Methods: The data of 19 patients operated from March 2017 to June 2017 were analyzed as a survey based assessment in Trakya University Hospital Department of Thoracic Surgery. Age, gender, satisfaction of having an implantable venous port catheter, the level of pain during implantation, being informed before the operation, fear of having a complication due to the implantable venous port catheter, being uncomfortable about having an implantable venous port catheter and not liking the appearance of implantable venous port catheter were included on the survey. The type and stage of cancer, comorbidity and the vein which is a port catheter was implanted in were recorded from patient charts.

Results: The mean age of participants was $61.44 \pm 7.493$ years. Out of all 10 (52.6\%) were male and $9(47.4 \%)$ were female. The most utilized side during insertion was right jugular vein (94.4\%). Rectum cancer was the most diagnosed cancer type with six patients. The most seen cancer stage was found to be stage-4-IV (66.7\%). Comorbidity was detected in 15 patients (83.3\%). 89.5\% of patients had indicated that they were informed enough before the procedure. $57.9 \%$ of the patients responded to question of fear of complication as "yes". According to these responses, 52.6\% of the patients emphasized their discomfort as "little".

Conclusion: This survey-based assessment study points out that most of the cancer patients are contented for being implanted with an implantable venous port catheter. Having an implantable venous port catheter is safer and easier way for cancer patients. Moreover, it gives patients more freedom of movement.

Keywords: Port catheter, patient satisfaction, survey

\section{INTRODUCTION}

Implantable venous port catheter (IVPC) is a widely used clinical tool with plenty of objectives such as parenteral nutrition, taking blood sample, management of medicines used in chemotherapy $(1,2)$. It is implanted in subcutaneous localization under local anesthesia (3). Subclavian vein or internal jugular vein are commonly preferred for implantation (4). IVPC is particularly applied to intermittent, long-term cancer patients (5). It has been reported that using IVPC on chemotherapy patients prevents venous toxicity caused by constantly opening venous channels (1). IVPC is an easier procedure for the patients because it is implanted under local anesthesia, promotes administration of chemotherapy, does not need special care, reduces pain and it does not require constantly opening venous channels $(3,5,6)$. Nevertheless, using IVPC can cause some problems. The most encountered complications are migration of catheter, infection and venous thrombosis (5). Furthermore artery puncture, pneumothorax, hemothorax, intravascular embolisms are also among the observed complications $(5,7)$. 
The aim of this study is to evaluate patient satisfaction regarding IVPC usage who came to Trakya University Faculty of Medicine Department of Thoracic Surgery between 20 March and 01 June 2017 in order to administrate catheter for facilitation of their chemotherapy treatment.

\section{MATERIAL AND METHODS}

This study was approved by Trakya University Faculty of Medicine Scientific Researches Ethics Committee. In this study, the data of 19 patients operated from March 2017 to June 2017 were analyzed with a survey based assessment in Trakya University Hospital Department of Thoracic Surgery.

Firstly, the patients with IVPC who volunteered to be in the study. The survey was filled after the IVPC operation of cancer patients. As appeal to hospital and demographic data; age, gender, satisfaction of having IVPC, the level of pain during implantation of the port catheter, being informed before the operation, fear of having a complication due to IVPC, being uncomfortable about having it and being disturbed by the appearance of IVPC were included on the survey (Table 1). In addition, the type and stage of cancer, comorbidity and the vein which is IVPC was implanted in were recorded from patients' charts.

Table 1: The questions in the survey

\begin{tabular}{|l|l|}
\hline 1) Age & \\
\hline 2) Gender & Male ( ) Female ( ) \\
\hline $\begin{array}{l}\text { 3) Are you satisfied with the imp- } \\
\text { lantation of port catheter? }\end{array}$ & Yes ( ) No ( ) \\
\hline $\begin{array}{l}\text { 4) Grade the pain that you feel } \\
\text { during the implantation of the port } \\
\text { catheter?. }\end{array}$ & $\begin{array}{l}\text { 1: None } \\
\text { 3: Partile } \\
\end{array}$ \\
$\begin{array}{l}\text { 4: Pretty much } \\
\text { 5: Intense }\end{array}$ \\
\hline $\begin{array}{l}\text { 5) Are you informed enough before } \\
\text { the implantation? }\end{array}$ & Yes ( ) No ( ) \\
\hline $\begin{array}{l}\text { 6) Are you afraid of having any } \\
\text { complication due to port catheter? }\end{array}$ & Yes ( ) No ( ) \\
\hline $\begin{array}{l}\text { 7) Grade how much you are distur- } \\
\text { bed by having a port catheter and } \\
\text { how often you think about it. }\end{array}$ & $\begin{array}{l}\text { 1: None } \\
\text { 2: Pittle }\end{array}$ \\
& $\begin{array}{l}\text { 4: Prtially much } \\
\text { 5: Too much }\end{array}$ \\
\hline $\begin{array}{l}\text { 8) Grade how much you are dis- } \\
\text { turbed by the appearance of port } \\
\text { catheter. }\end{array}$ & $\begin{array}{l}\text { 1: None } \\
\text { 2: Little } \\
\text { 3: Partially } \\
\text { 4: Pretty much } \\
\text { 5: Too much }\end{array}$ \\
\hline
\end{tabular}

Since this study is based on descriptive statistics, continuous variables are expressed as mean \pm standard deviation and categorical variables are expressed as numbers and percentages. All statistical analyses were performed using SPSS.

\section{RESULTS}

This survey-based study was conducted among 20 patients inserted IVPC in Trakya University Faculty of Medicine, Department of Thoracic Surgery. One patient was excluded due to missing data so, 19 patients were included in the study.

The mean age of participants was $61.44 \pm 7.493$ years. Out of all $10(52.6 \%)$ were male and $9(47.4 \%)$ were female. The most utilized side during insertion was right jugular vein (94.4\%). Different types of cancer such as rectum, breast, colon, pancreas, stomach and larynx have seen among the patients and rectum cancer was the most diagnosed cancer type with six patients. Furthermore, the most common cancer stage was found as stage4-IV (66.7\%). Comorbidity was detected in 15 (83.3\%) patients. $89.5 \%$ of patients had indicated that they were informed enough before the procedure. However, 57.9\% of the patients responded to question of fear of complication as "yes". 52.6\% of the patients defined their discomfort as "little". Moreover, the distribution of patients' answers to the question which is about the disturbance of appearance of port catheter was shown in Figure 1.

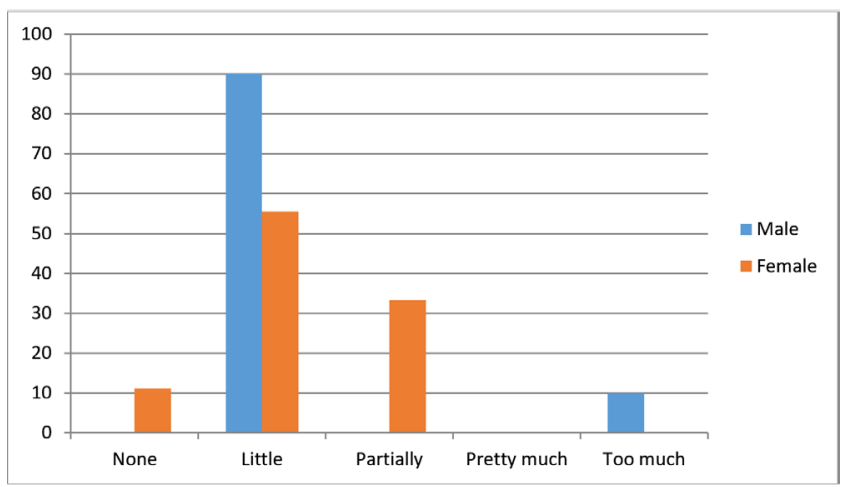

Figure 1: The distribution of answers to the question 8

Likewise, the grade of the pain that was felt during the implantation of port catheter was indicated in Figure 2. With all the results considered, it was found that $100 \%$ of the patients were satisfied. 


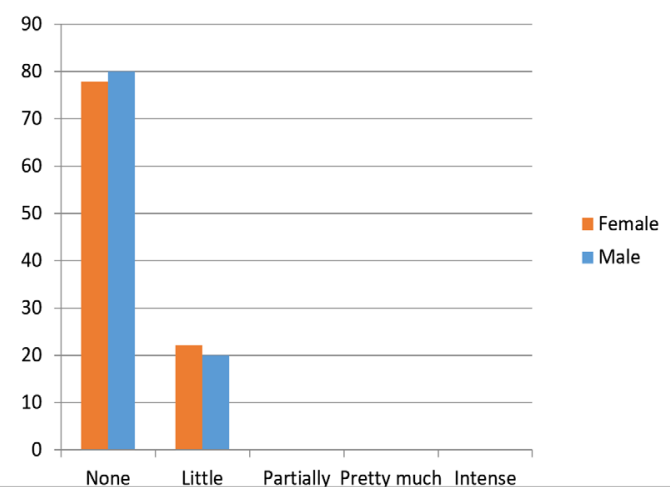

Figure 2: The grade of the pain that was felt during the implantation of the port catheter

\section{DISCUSSION}

Researchers commonly focus on complications due to its usage. However, evaluating patient satisfaction and quality of life regarding catheter usage are crucial issues. A survey-based assessment conducted by Nagel et al. (6) has reported that negative effects of using the port catheter have low effects on daily life and also IVPC increased the patient satisfaction. In addition, a questionnaire-based survey conducted by Kreis et al. (7) has emphasized the significance of informing the patients before implantation of the port catheter.

Indwelling catheters are appliances of great rank broadly used in the administration of chemotherapy to cancer patients worldwide (8). They provide comfort, accessibility and safety in the application of chemotherapy, which when managed by peripheral vein, may generate complications, such as pain, phlebitis, skin necrosis and compartment syndrome (9). In an effort to explain the satisfaction of cancer patients that are having port catheters, a questionnaire was conducted among 19 patients who had IVPC implantation.

In this study, $100 \%$ of the patients said that they were "satisfied" to have a port catheter. The reason for this may be that patients prefer one time needle insertion instead multiple needle insertions. Furthermore, chemotherapy takes less time with catheter. Moreover, some patients can be treated at their homes with chemotherapy pump via IVPC. It provides long-term accessibility which is preferred for cancer patients who get chemotherapy for years. Including both male and female patients, $78.9 \%$ of 19 people selected "little" from the questionnaire for the pain that they felt during the catheter insertion. In addition, in the study of Nager et al. (7) the pain of insertion was found to have no effect on patient satisfaction. Mo- reover, fear of complication is rated as "a little bit" in the questionnaire of the study of H.Kreis et al. (6) and also in the same study it is reported that "a little bit" choice for pain of implantation is the remarkable result which is similar to our study. The results of this study and other recent studies show that implantation of the port catheter is not an extremely painful process for the patients.

In addition, port catheters are mostly inserted to right jugular vein. The jugular vein is preferred because it is extremely close to the skin and simple to locate with ultrasound. It runs straight down to the heart and has the lowest risk for problems during placement of the catheter (10). As it is shown that in the study of Nagel et al. (7) $83.7 \%$ of the population has right jugular vein inserted port. Our data reveals that $94.4 \%$ of the patients has right jugular vein inserted port when compared with Nagel's study.

The percentage of the patients who stage 4-IV cancer is $63.2 \%$. According to these consequences, in the patients who have attended this study, IVPC is mostly used for cancer stage 4-IV. Moreover fear of complication is another encounter that the patients had to face.

In current literature, there are a lot of examples for complications in catheter placement (6). In this study, $57.9 \%$ of the patients are having fear of complication. Even $89.5 \%$ of the patients thought that they were informed enough before the procedure, they are still afraid of complication. It is found that $44.4 \%$ of the patients are overall satisfied with IVPC in the research of H.Kreis et al. (6), but in our study satisfaction of the patients revealed $100 \%$.

As a conclusion, this survey-based assessment study points out that most of the cancer patients are contented for being implanted with a port catheter. Having an IVPC is safer and easier way during treatment and follow up period for cancer patients. Moreover, it gives more freedom of movement.

Although, the survey has reached its aims, the small number of patients might limit our conclusion. However, further studies including more patients and long term follow-up intervals are needed. 
Ethics Committee Approval: This study was approved by Scientific Researches Ethics Committee of Trakya University Medical Faculty.

Informed Consent: Written informed consent was obtained from the participants of this study.

Conflict of Interest: The authors declared no conflict of interest.

Financial Disclosure: The authors declared that this study received no financial support.

\section{REFERENCES}

1. Ignatov A, Hoffman O, Smith B et al. An 11-year retrospective study of totally implanted central venous access ports: complications and patient satisfaction. European Journal of Surgical Oncology 2009;35:241-6.

2. Liberale G, Houkayem M, Viste C et al. Evaluation of the perceptions and cosmetic satisfaction of breast cancer patients undergoing totally implantable vascular access device (TIVAD) placement. Support Care Cancer 2016;24:5035-40.

3. Kesici S, Carus H, Turgut $\mathrm{N}$ et al. Spontaneous migration of a central venous catheter after successful catheterization: case report. Okmeydanı Tip Dergisi 2011;27(1):49-53.

4. Karamustafaoglu A, Yoruk Y, Tarladacalısır T et al. Implantations of central venous ports with chest catheter insertion via the subclavian vein in oncology patients: a single center experience. Acta Oncologica Turcica 2009;42:105-8.

5. Dogan V, Kayalı S, Ertugrul I et al. Percutaneous retrieval of a venous port catheter embolizing to pulmonary artery with a snare loop catheter; a case report and review of the literature. Çağdaş Tip Dergisi 2015;5(1): 54-6.

6. Kreis H, Loehberg C R, Lux M P et al. Patients' attitudes to totally implantable venous access port systems for gynecological or breast malignancies. European Journal of Surgical Oncology 2007;33:39-43.

7. Nagel S N, Teichgräber U K M, Kausche S et al. Satisfaction and quality of life: a survey-based assessment in patients with a totally implantable venous port system. European Journal of Cancer Care 2011;21:197-204.
8. Kock HJ, Pietsch M, Krause U et al. Implantable vascular access systems: experience in 1500 patients with totally implantable venous port systems. World J Surg. 1998;22(1):12-6.

9. Fonseca I, Krutman M, Nishinari K et al. Brachial insertion of fully implantable venous catheters for chemotherapy: complications and quality of life assessment in 35 patients. Einstein 2016;14(4):473-9.

10. Dichmann R, Erickson T, Kennedy A et al. What is a port-a-cath? (cited: 2017 May 22) Available from: URL:http://www.missionhopecancercenter.com/port-acath.php. 